\section{Preliminary Development of a Brief Intervention to Prevent Alcohol Misuse and Enhance Sport Performance in Collegiate Athletes}

\section{Abstract}

Alcohol abuse prevention and mental sport performance programming are becoming increasingly significant in collegiate athletics. There are certainly advantages in the integrated provision of these intervention approaches. However, substance abuse professionals rarely address sport performance, and sport performance experts rarely address alcohol abuse prevention. Therefore, in this clinical trial, 201 NCAA athletes were randomly assigned with a significant other to participate in brief assessment, goal development, and contingency contracting or a wait-list control after completing the Sport Interference Checklist (SIC) and Alcohol Use Disorders Identification Test (AUDIT). Results indicated that participants who were randomly assigned to the experimental program, as compared with participants who were assigned to the control group, reported significant decreases in alcohol consumption (AUDIT), dysfunctional thoughts and stress in competitive sporting events and academic and injury management factors that interfere with training, from baseline to 2 months post-baseline. No differences were found between the experimental groups in other SIC subscales. Future directions are discussed in light of the results.

Keywords: Student-athlete; Alcohol prevention; Goals; Contingency contracting; Sport performance

\author{
Brad Donohue, \\ Travis Loughran, \\ Michelle Pitts, \\ Yulis Gavrillova, \\ Griag M Chow, \\ Arturo-Soto-Nevarez and \\ Kimberly Schubert
}

University of Nevada, Las Vegas, USA

Corresponding author: Brad Donohue

$\equiv$ Bradley.donohue@gmail.com

Ph.D., University of Nevada, Department of Psychology, 4505 S. Maryland Parkway, Las Vegas, NV 89154, USA.

Tel: $702-895-2468$

Citation: Donohue B, Loughran T, Pitts $M$, et al. Preliminary Development of a Brief Intervention to Prevent Alcohol Misuse and Enhance Sport Performance in Collegiate Athletes. J Drug Abuse. 2016, 2:3.

Received: September 14, 2016; Accepted: September 29, 2016; Published: October 06, 2016

\section{Introduction}

Student-athletes are at high-risk to experience problems due to alcohol intoxication, influencing professionals to recommend the empirical development of effective alcohol prevention programs in this population [1-5] Eighty percent of studentathletes are estimated to have consumed alcohol in the past year [6] and almost half of these student-athletes have reported at least one heavy drinking episode [5]. Most studies that have examined the relationship between sports involvement and alcohol consumption have demonstrated a significant positive association [7, 8] Cultural and environmental factors appear to influence heavier use of alcohol in student-athletes $[8,9]$ Student athletes are more likely to engage in "binge" drinking $(61 \%$ of males, $50 \%$ of females) than their non-athlete counterparts (43\% of males, $36 \%$ of females; Wechsler [10]. A recent report by the NCAA on student-athlete drinking habits reported harmful alcohol use patterns. More than half of the collegiate athletes sampled reported alcohol consumption after practice or competition. Male student-athletes comprised the highest rates of excessive alcohol use; $18 \%$ consuming 10 or more alcoholic drinks in one sitting [11].

Student-athletes are more likely to experience negative consequences due to alcohol use compared to non-student athletes [7, 12, 13], including injuries from driving under the influence, academic problems, relationship problems, legal problems, and unprotected sex [12-14]. Student-athletes, as compared with non-athletes, are more likely to binge when they drink alcohol, intentionally drink alcohol to become intoxicated, and drink until intoxicated several times a month [1, 14, 15]. Athletes who drink alcohol at least once per week have been found to be twice as likely to experience injury, as compared with athletes who do not drink alcohol [13]. Some studies 
indicate that alcohol use in student-athletes is likely to intensify throughout college $[16,17]$ and rates of binge drinking continue to be relatively high after collegiate sports are discontinued [14, 18]. Freshman student-athletes are at particular risk of death or serious injury due to alcohol intoxication $[19,20]$. Thus, there is a great need to develop alcohol abuse prevention programs in collegiate athletes, particularly during their freshman year.

Although alcohol education-based prevention programs have been relatively ineffective in reducing collegiate student alcohol use [21] particularly in collegiate athletes [6], these programs are the primary approach utilized by universities to address alcohol misuse [22, 23]. Indeed, more than 400 colleges have adopted alcohol education programs, sanctioning, and referrals to campus counseling programs when substance use has been determined to be clinically problematic in athletes (i.e., Athletic Prevention, Programming and Leadership Education [APPLE] [24, 25]. Effect sizes for these programs are small and often non-impactful $[21,26]$.

In contrast, other techniques have shown promising outcomes in the prevention of alcohol consumption, particularly those that include motivational interventions, and significant other involvement (e.g. parents). Brief motivational interventions (BMIs) for alcohol abuse prevention are focused on increasing motivation and commitment to reduce problematic use and are typically delivered in one to two sessions [27]. These approaches to alcohol misuse appear to be promising in studentathlete populations [6] and complement educationally-based programming by offering personalized feedback in regards to alcohol use and harm-reduction skills training [28]. The Alcohol Use Disorders Identification Test (AUDIT) is a validated measure in which to examine alcohol use in student-athletes, and permits provision of individualized feedback based on normative rates $[29,30]$. In their review of the outcome literature [31] found the majority of evidence-supported interventions for alcohol misuse involved the provision of feedback about alcohol use. Along these lines, feedback should ideally be individualized [32] and include goal development [33].

According to social norms theory, college students overestimate alcohol use of their peers, influencing them to increase their own rates of alcohol use in an effort to be consistent with peers. Studies in student-athletes have been found to support this theory [4, 34]. Therefore, interventions have been developed to address the importance of social norm comparisons through normative feedback that is specific to alcohol use patterns in teammates and other peers [35].

Several reviews of the literature highlight the need to develop more efficacious interventions aimed at reducing alcohol use in athletes [2, 36] determined that a computerized personalized feedback program with social norming was effective in lowering alcohol use in a subgroup of student-athletes who were classified as high-risk drinkers, relative to an education-only control condition of student-athletes. This trial included a relatively small number of participants ( $n=33$ at follow-up). However, results were replicated with a larger sample $(n=113)$ [35]
Cimini [37] conducted a study with 170 student-athletes. One condition included the Brief Alcohol Screening and Intervention for College Students (BASICS; [38] with an addition of athletespecific content (e.g. effects of drinking on athletic performance) and the other was a control condition. Student-athletes who were screened to be "at-risk" drinkers demonstrated significant between-group increases in their use of protective behavioral strategies during drinking and corrections in norm perceptions of alcohol use among peers, compared to participants in the control condition. The intervention condition resulted in significant reductions in alcohol use scores. However, there were no differences in alcohol use between the intervention condition and control group.

Martens [39] conducted a randomized controlled study in 263 student-athletes. The study included three intervention conditions: computerized personalized feedback, computerized personalized feedback program tailored for athletes, and an education-only condition. There were no group differences in alcohol outcomes between conditions. However, the studentathlete tailored condition resulted in significantly lower peak drinking when heavy drinkers $(n=61)$ were examined. The athlete-specific feedback incorporated into the program included summarizing athlete-specific negative consequences of drinking (e.g. being hung-over at a game or practice) and the impact of heavy alcohol use on athletic performance. Results suggest that targeting information to athletes may be an important component in alcohol prevention as the outcomes of such tailored information is superior.

A growing body of research indicates that college students' alcohol-related beliefs are influenced by their parents [40]. For instance, in a controlled clinical trial, Turrisi [41] determined, that substance use rates of incoming freshman athletes were significantly reduced after parents were provided literature to assist them in the prevention of alcohol misuse [42] recruited a sample of college freshman who were former high school athletes $(n=1,275)$ for this study, randomizing them to one of four conditions: BASICS, BASICS with parent support, and an assessment-only control. The combined parent and BASICS condition, which was delivered to students just prior to entering college, resulted in significantly lower alcohol consumption, highrisk drinking, and consequences at follow-up, compared to the assessment control condition.

Based on the reviewed literature, personalized feedback about alcohol misuse and goal-setting appear to be efficacious components in reducing alcohol consumption. Research is needed, however, to evaluate the efficacy of BMIs that incorporate contingency management strategies that are aimed at reducing factors that reportedly interfere with sport performance in student athletes, particularly when parents [6, 28], coaches [43] and teammates are incorporated into programming. Alcohol abuse prevention interventions with student-athletes also appear to be particularly relevant for use in newly enrolled student athletes who are transitioning into university life [44] and that address sport performance and athlete-specific factors [3].

Therefore, we conducted a randomized controlled trial to examine 
the effects of an experimental program for freshman collegiate student-athletes that emphasizes involvement of supportive others, brief assessment, goal construction, and contingency management. We hypothesized that participants who were assigned to the experimental program, relative to participants in a no intervention control condition, would significantly reduce alcohol consumption and factors that reportedly interfere with sport performance from baseline to two-month post-baseline.

\section{Methods}

\section{Participants}

Participants were 201 incoming collegiate athletes (110 female; 91 male) who were referred to the study by the university athletic department. All athletes were required to be at least 18 years old and formally participating in a NCAA sport. The study was approved by an institutional review board for research involving human subjects, and no adverse events were reported. Demographic characteristics of participants are presented in (Table 1)

Table 1 Characteristics of Student Athletes with Numbers Shown as Frequency (\%).

\begin{tabular}{|c|c|c|c|c|c|}
\hline $\begin{array}{c}\text { Athlete } \\
\text { Characteristic }\end{array}$ & $\begin{array}{c}\text { Total } \\
\text { (N=201) }\end{array}$ & $\begin{array}{l}\text { Year } 1 \\
(\mathrm{~N}=64)\end{array}$ & $\begin{array}{c}\text { Year } 2 \\
\text { (N=137) }\end{array}$ & $\begin{array}{c}\text { Experimental } \\
\text { Condition } \\
\text { (N=101) }\end{array}$ & $\begin{array}{l}\text { Control } \\
\text { Condition } \\
(\mathrm{N}=100)\end{array}$ \\
\hline Mean Age & $\begin{array}{l}18.92 \\
(1.14)\end{array}$ & $\begin{array}{l}18.77 \\
(1.15)\end{array}$ & $\begin{array}{l}18.99 \\
(1.13)\end{array}$ & 18.95 (1.15) & $\begin{array}{l}18.89 \\
(1.14)\end{array}$ \\
\hline \multicolumn{6}{|l|}{ Gender } \\
\hline Male & $91(45.3)$ & $32(50.0)$ & $59(43.1)$ & $46(45.5)$ & 45 (45.0) \\
\hline Female & $110(54.7)$ & $32(50.0)$ & 78 (56.9) & 55 (54.5) & \\
\hline \multicolumn{6}{|l|}{ Ethnicity } \\
\hline Caucasian & $97(48.3)$ & 25 (39.1) & $72(52.6)$ & $46(45.5)$ & 51 (51.0) \\
\hline $\begin{array}{l}\text { Black/African } \\
\text { American }\end{array}$ & 30 (14.9) & $16(25.0)$ & $14(10.2)$ & 15 (14.9) & 15 (15.0) \\
\hline $\begin{array}{l}\text { Asian/Asian } \\
\text { American }\end{array}$ & $8(4.0)$ & $3(4.7)$ & $5(3.6)$ & $6(5.9)$ & $2(2.0)$ \\
\hline Hispanic/Latino & $21(10.4)$ & $4(6.3)$ & $17(12.4)$ & $13(12.9)$ & $8(8.0)$ \\
\hline Pacific Islander & $12(6.0)$ & $8(12.5)$ & $4(2.9)$ & $5(5.0)$ & $7(7.0)$ \\
\hline Other & 33 (16.4) & $8(12.5)$ & 25 (18.3) & 16 (15.9) & 17 (17.0) \\
\hline \multicolumn{6}{|l|}{ Sport } \\
\hline Baseball & $16(8.0)$ & $0(0.0)$ & $16(11.7)$ & $8(7.9)$ & $8(8.0)$ \\
\hline Basketball & $4(2.0)$ & $2(3.1)$ & $2(1.5)$ & $4(4.0)$ & $0(0.0)$ \\
\hline Cheer \& Dance & $25(12.4)$ & $4(6.3)$ & $21(15.3)$ & 14 (13.9) & 11 (11.0) \\
\hline Cross Country & $2(1.0)$ & $2(3.1)$ & $0(0.0)$ & $0(0)$ & $2(2.0)$ \\
\hline Football & 40 (19.9) & $21(32.8)$ & 19 (13.9) & 20 (19.8) & $20(20.0)$ \\
\hline Golf & $6(3.0)$ & $0(0.0)$ & $6(4.4)$ & $4(4.0)$ & $2(2.0)$ \\
\hline Soccer & 33 (16.4) & 10 (15.6) & $23(16.8)$ & 12 (11.9) & $21(21.0)$ \\
\hline Softball & $11(5.5)$ & $5(7.8)$ & $6(4.4)$ & $5(5.0)$ & $6(6.0)$ \\
\hline $\begin{array}{l}\text { Swimming \& } \\
\text { Diving }\end{array}$ & 23 (11.4) & 10 (15.6) & $13(9.5)$ & 14 (13.9) & $9(9.0)$ \\
\hline Tennis & $8(4.0)$ & $0(0.0)$ & $8(5.8)$ & $3(3.0)$ & $5(5.0)$ \\
\hline Track \& Field & 24 (11.9) & $8(12.5)$ & $16(11.7)$ & 11 (10.9) & $13(13.0)$ \\
\hline Volleyball & $9(4.5)$ & $2(3.1)$ & $7(5.1)$ & $6(5.9)$ & $3(3.0)$ \\
\hline
\end{tabular}

Note: Numbers in parentheses after age are standard deviations not percentages.

\section{Experimental design}

A 2 (experimental condition: experimental prevention intervention, no prevention control) $\times 2$ (time: baseline, 2 month follow-up) between groups design with random assignment of athletes to conditions was utilized. Immediately after completion of baseline assessment, all participants were randomized into either the experimental or control condition. Each participant was notified of their experimental condition assignment by telephone.

\section{Procedure}

Recruitment : In consecutive spring semesters, the institution's athletic department assembled all incoming student-athletes for a mandatory meeting that was specific to the prevention of alcohol misuse. At this meeting student-athletes were informed that the current study was a voluntary option available to satisfy the substance abuse prevention class requirements of the institution's athletic department. Student-athletes who chose not to participate in the study were referred to a standard psychoeducational class on substance use prevention as customarily provided by the athletic department. Studentathletes who were interested in study participation completed informed consent and baseline assessment measures, including demographic and outcome variables.

\section{Method of collecting data}

Baseline assessments were administered immediately after student-athletes provided informed consent. Two months after randomization, athletes were scheduled for their follow-up assessment.

\section{Method of retaining participants in the study}

Figure 1 depicts how student-athletes entered and were retained or exited from the study. A total of 201 student-athletes consented for the study and completed baseline assessment measures. All student-athletes who consented to participate and completed baseline assessment measures were randomly assigned. One hundred and one student-athletes were assigned to the experimental condition and 100 were assigned to the no-prevention control condition. Of the 101 assigned to the experimental condition, 86 (85\%) attended the scheduled prevention meeting. Ninety-three (92\%) student-athletes assigned to the experimental condition completed two-month follow-up assessment, while 89 (89\%) in the no-prevention control condition completed two-month follow-up assessment.

\section{Experimental Conditions}

\section{Experimental prevention program}

The experimental condition was an abbreviated version of the contingency management module of The Optimum Performance Program in Sports [9] and consisted of a one hour meeting with a supportive other, brief assessment, goal development, and contingency management. Approximately 1 week prior to receiving the intervention prevention, participants who were assigned to the experimental condition were solicited to provide a ranked list of individuals who they would prefer to attend the 


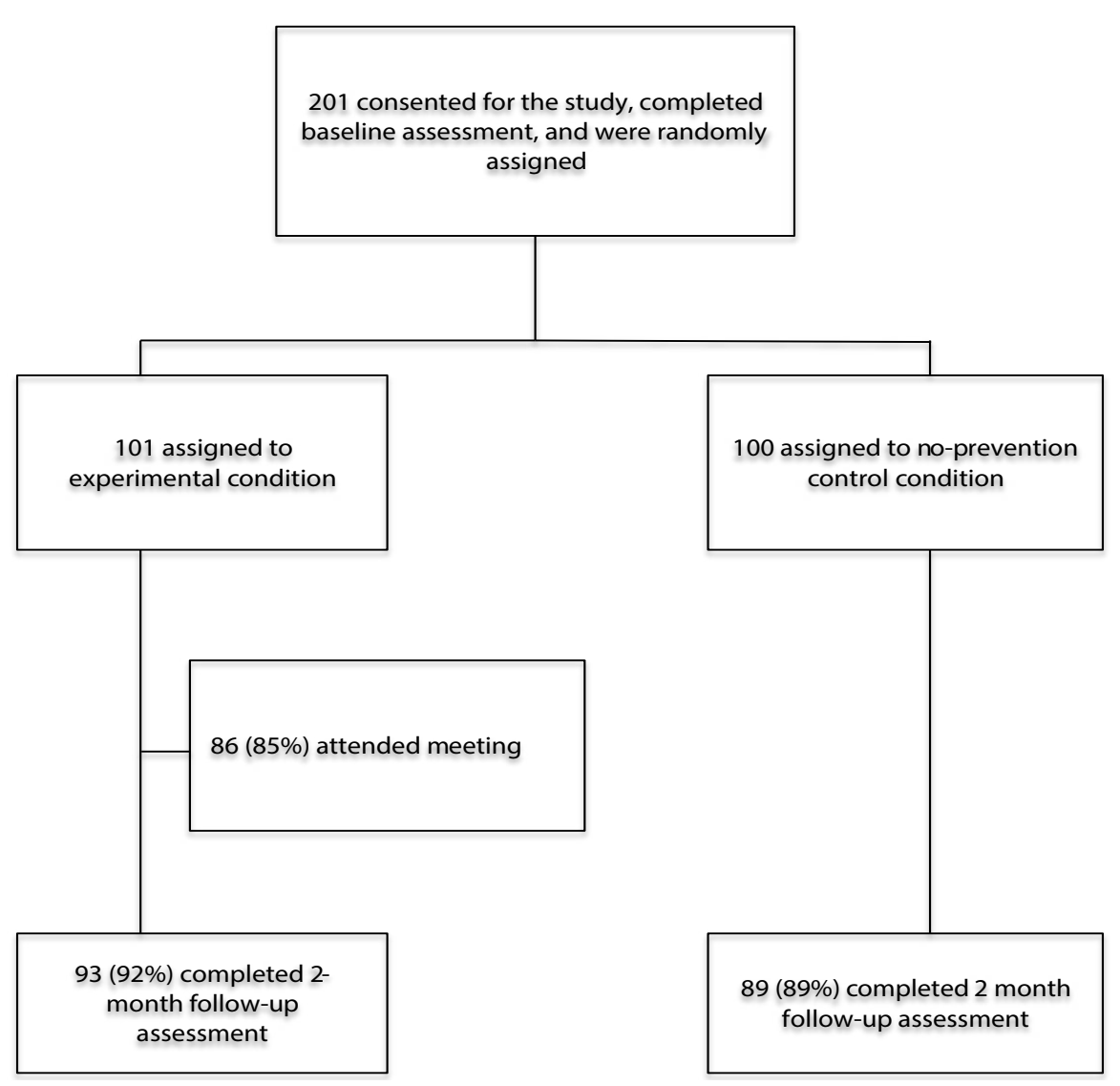

Figure 1 Flowchart of participant entry and exit in study.

experimental program meeting with them. The research team attempted to recruit one supportive other from each participant's list to attend the experimental program with the respective participant. Parents were prioritized over other significant others because Turrisi et al. [41] found the inclusion of parents assisted alcohol abuse prevention programming in their study involving student athletes. During the first year, the significant others were permitted to join the participants in their intervention prevention meeting through telephone- or video-conferencing, or in-person contact, and during the second year all participation was restricted to in-person contact. Each participant in year one received the experimental program condition in a one-hour individual meeting with a performance coach and the selected significant other. Each participant in year two attended the experimental program meeting with one significant other and up to 7 other participants and their significant others. Participants were provided feedback about their baseline assessment scores. Alcohol use and each troublesome behavior or thought identified to interfere with sport performance training and competition from baseline assessment measures was converted into a performance-oriented goal. Supportive others were prompted to contingently reward goal achievement. Showing participants and their significant others a list of standardized goals and rewards assisted in establishing contingencies rapidly. Participants were provided a goals worksheet that included their developed goals and participants were encouraged by the performance coaches to monitor their goals each night with the significant other, whenever feasible. Supportive others were encouraged to provide contingent rewards to the extent goals were accomplished. Experimental programming in year one and year two were essentially the same, with the exception that year one meetings involved the participant and invited supportive other (via telephone or video-conferencing, Skype or personal contact) while in year 2 the meetings occurred in groups of up to 8 participants and their significant others.

No-prevention control condition. Participants who were randomized to the control condition were not provided programming.

\section{Measures}

Sport Interference Checklist (SIC). The SIC [45] is a 26-item self-report inventory, which assesses a wide range of cognitive and behavioral problems that commonly interfere with sport performance. Participants are prompted to report the extent to which various factors interfere with their sport performance in training (Problems in Sport Training Scale, PSTS) and in competition (Problems in Sport Competition Scale, PSCS), utilizing a sevenpoint response scale ( $1=$ Never, $7=$ Always). The PSTS includes four factors (Dysfunctional Thoughts and Stress, Academic Problems, Injury Concerns and Poor Team Relationships) and the PSCS includes six factors (Dysfunctional Thoughts and Stress, Academic and Adjustment Problems, Lack of Motivation, Overly Confident/Critical, Injury Concerns and Pain Intolerance). Initial 
psychometric evaluation of the SIC showed excellent reliability and validity [45].

The Alcohol Use Disorders Identification Test (AUDIT). AUDIT [30] is a 10-item self-report questionnaire designed to detect hazardous or harmful levels of alcohol consumption. This screening test was developed by the World Health Organization as a method of screening for excessive drinking, and to assist in brief assessment. A briefer version of AUDIT, which includes AUDIT questions 1 to 3 ("How often do you have a drink containing alcohol?" "How many standard drinks containing alcohol do you have on a typical day?" "How often do you have six or more drinks on one occasion?") is specific to alcohol consumption (AUDIT-C) and has been found to be practical and valid for screening alcohol and dependence. Higher scores indicate greater severity of alcohol consumption. For detection of heavy drinking, AUDIT-C was found to perform better than the AUDIT. Therefore, this study examined alcohol consumption utilizing the AUDIT-C.

\section{Results}

\section{Demographic comparision of participants in year one and two}

As indicated earlier, participants in year one who received the experimental condition received slightly different applications of the experimental program than participants in year two who were assigned to the experimental condition (i.e., individual vs. group meetings). Therefore, analyses were conducted to explore potential demographic differences between participants receiving the experimental program in year one of the study and experimental program participants in year two of the study. Chisquare analyses were used to examine categorical demographic variables (sport type, gender) and one-way analysis of variance (ANOVAs) was used to examine the continuous demographic variable age. Based on these analyses, no significant demographic differences were found (all ps>0.05).

\section{Comparison of experimental conditions in study retention}

Potential differences in the completion of follow-up assessment between participants in the experimental condition and participants in the control condition were examined utilizing chisquare analyses. There was no significant difference between participants in the two conditions regarding their completion of follow-up assessment (all ps>0.05).

\section{Comparison of experimental conditions at the baseline}

Potential pre-treatment differences between participants in the experimental conditions were examined utilizing chi-square analyses on ethnicity, gender, and type of sport and baseline categorical demographic variables. One-way analyses of variance (ANOVAs) were performed on age and primary outcome variables. Based on these analyses, no significant baseline differences were found between the experimental condition and the control condition (all ps>0.05).

\section{Primary analyses examining alcohol consumption}

Means and standard deviations of outcome measures for the experimental condition and control group are presented separately for baseline and two-month follow-up in Table 2 . Participants who completed baseline and two-month followup assessments were included in the analyses $(\mathrm{N}=182)$. An analysis of covariance (ANCOVA) was conducted to examine differences between experimental conditions at 2 month follow-up on alcohol consumption (AUDIT-C) while controlling baseline AUDIT-C scores. There was a significant main effect between participants in the experimental conditions on AUDIT-C scores at two-month follow-up after accounting for baseline AUDIT-C scores $F(1,179)=4.12, p=0.04$. This result indicates that AUDIT-C scores at 2-month follow-up were significantly lower for participants in the experimental condition compared to participants in the control condition after considering baseline scores (partial $\eta^{2}=0.02$ ). Thus, the experimental program was more efficacious in reducing alcohol consumption at 2 month follow-up assessment, controlling for baseline scores.

\section{Primary analyses examining factors interfering with sport performance}

Analyses of covariance (ANCOVAs) were conducted to examine Training and Competition subscale scores derived from the Sport Interference Checklist [45] at 2 month follow-up while controlling for baseline scores. Means and standard deviations for the SIC training and competition subscales are presented in Table 2.

\section{Academic problems in training}

There was a significant main effect between conditions for SIC academic problems in training subscale score at 2 month followup after controlling for the effect of baseline SIC academic problems in training subscale score $F(1,179)=5.29, p=0.02$. This result indicates that SIC academic problems in training scores in the experimental condition were significantly lower at 2 month follow up compared to the control condition (partial $\eta^{2}=0.03$ ).

\section{Injury concerns in training}

There was a significant main effect between conditions for SIC injury concerns in training subscale score at 2 month follow-up after controlling for the effect of baseline SIC injury concerns in training subscale score $F(1,179)=4.04, p=0.05$. This result indicates that SIC injury concerns in training scores in the experimental condition were significantly lower at 2 month follow up compared to the control condition (partial $\eta^{2}=0.02$ ).

\section{Dysfunctional thoughts and stress in training}

There was no significant main effect between conditions for SIC dysfunctional thoughts and stress in training subscale score at 2 month follow-up after controlling for the effect of baseline SIC dysfunctional thoughts and stress in training subscale score $F(1,179)=2.75, p=0.10$, partial $\eta^{2}=0.02$.

Poor team relationships in training. There was no significant main effect between conditions for SIC poor team relationships 
Table 2 Means and standard deviations for AUDIT consumption and sport interference checklist subscales.

\begin{tabular}{|c|c|c|c|c|}
\hline \multirow[t]{2}{*}{ Variable } & \multicolumn{2}{|c|}{ Experimental $(N=93)$} & \multicolumn{2}{|c|}{ Control $(N=89)$} \\
\hline & Pre & Post & Pre & Post \\
\hline *Audit Consumption & $2.18(2.46)$ & $1.74(1.86)$ & $2.30(2.33)$ & $2.18(2.17)$ \\
\hline $\begin{array}{c}\text { *SIC PSCS } \\
\text { Dysfunctional } \\
\text { Thoughts and Stress }\end{array}$ & $2.30(1.15)$ & $1.99(0.90)$ & $2.59(1.32)$ & $2.44(1.16)$ \\
\hline $\begin{array}{l}\text { SIC PSCS Academic } \\
\text { and Adjustment } \\
\text { Problems }\end{array}$ & $1.61(0.84)$ & $1.52(0.74)$ & $1.76(0.93)$ & $1.75(1.04)$ \\
\hline $\begin{array}{l}\text { SIC PSCS Lack of } \\
\text { Motivation }\end{array}$ & $1.42(0.70)$ & $1.37(0.63)$ & $1.52(0.80)$ & $1.52(0.75)$ \\
\hline $\begin{array}{l}\text { SIC PSCS Overly } \\
\text { Confident and } \\
\text { Critical }\end{array}$ & $1.46(0.63)$ & $1.47(0.72)$ & $1.70(0.84)$ & $1.70(0.92)$ \\
\hline $\begin{array}{l}\text { SIC PSCS Injury } \\
\text { Concerns }\end{array}$ & $1.68(1.07)$ & $1.52(0.87)$ & $1.99(1.28)$ & $1.84(1.22)$ \\
\hline $\begin{array}{l}\text { SIC PSCS Pain } \\
\text { Intolerance }\end{array}$ & $1.38(0.63)$ & $1.31(0.59)$ & $1.62(0.85)$ & $1.58(0.87)$ \\
\hline $\begin{array}{c}\text { SIC PSTS } \\
\text { Dysfunctional } \\
\text { Thoughts and Stress }\end{array}$ & $2.48(1.19)$ & $2.23(0.96)$ & $2.99(1.45$ & $2.73(1.27)$ \\
\hline $\begin{array}{c}\text { *SIC PSTS Academic } \\
\text { Problems }\end{array}$ & $1.93(1.11)$ & $1.78(0.92)$ & $2.05(1.04)$ & $2.16(1.19)$ \\
\hline $\begin{array}{l}\text { *SIC PSTS Injury } \\
\text { Concerns }\end{array}$ & $1.54(0.75)$ & $1.45(0.66)$ & $1.84(0.93)$ & $1.78(0.89)$ \\
\hline $\begin{array}{l}\text { SIC PSTS Poor Team } \\
\text { Relationships }\end{array}$ & $1.54(0.87)$ & $1.52(0.78)$ & $1.72(1.04)$ & $1.81(1.08)$ \\
\hline
\end{tabular}

Note: Audit Consumption scores can range from 0 to 12 . SIC scores can range from 1 to 7 . Standard deviations are in parentheses.

*Treatment by time interaction effect $(p<0.05)$

in training subscale score at 2 month follow-up after controlling for the effect of baseline SIC poor team relationships in training subscale score $F(1,179)=2.64, p=0.11$, partial $\eta^{2}=0.02$.

\section{Dysfunctional thoughts and stress in competition}

There was a significant main effect between conditions for SIC dysfunctional thoughts and stress in competition subscale score at 2 month follow-up after controlling for the effect of baseline SIC dysfunctional thoughts and stress in competition subscale score $F(1,179)=5.70, p=0.02$. This result indicates that SIC dysfunctional thoughts and stress in competition scores in the experimental condition were significantly lower at 2 month follow up compared to the control group (partial $\eta^{2}=0.03$ ).

\section{Academic and adjustment problems in competition}

There was no significant main effect between conditions for SIC academic and adjustment problems in competition subscale score at 2-month follow-up after controlling for the effect of baseline SIC academic and adjustment problems in competition subscale score $F(1,179)=1.80, p=0.18$, partial $\eta^{2}=0.01$.

\section{Lack of motivation in competition}

There was no significant main effect between conditions for $\mathrm{SIC}$ lack of motivation in competition subscale score at 2 month follow-up after controlling for the effect of baseline SIC lack of motivation in competition subscale score $F(1,179)=1.33, p=0.25$, partial $\eta^{2}=0.01$.

\section{Overly confident/critical in competition}

There was no significant main effect between conditions for SIC overly confident/critical in competition subscale score at 2 month follow-up after controlling for the effect of baseline SIC overly confident/critical in competition subscale score $F(1,179)=0.63$, $p=0.43$, partial $\eta^{2}=0.00$.

\section{Injury concerns in competition}

There was no significant main effect between conditions for SIC injury concerns in competition subscale score at 2 month followup after controlling for the effect of baseline SIC injury concerns in competition subscale score $F(1,179)=1.44, p=0.23$, partial $\eta^{2}=0.01$

\section{Pain intolerance in competition}

There was no significant main effect between conditions for SIC pain intolerance in competition subscale score at 2 month followup after controlling for the effect of baseline SIC pain intolerance in competition subscale score $F(1,179)=2.95, p=0.09$, partial $\eta^{2}=0.02$.

\section{Discussion}

Alcohol consumption in student-athletes is a growing concern on college campuses. Indeed, student-athletes are more at risk for unhealthy drinking patterns and negative consequences compared to non-athlete counterparts. Previous examinations of alcohol abuse prevention methods for student-athletes shows mixed results and none of the reviewed programs have targeted or decreased cognitive and behavioral problems that interfere with sport performance. Therefore, the purpose of this study was to examine the efficacy of an experimental program that included brief assessment, goal construction, contingency management, and inclusion of student athletes' significant others. Results showed participants in the experimental condition significantly reduced their alcohol consumption from baseline to 2 months post-randomization compared with student-athlete participants in the control condition. The experimental condition also led to significant reductions in a few factors that reportedly interfere with sport training (i.e., academic problems, injury concerns) and sport competition (i.e., dysfunctional thoughts and stress), as compared with participants in the control condition. These results support the hypothesis that brief assessment, goal construction, contingency management and involvement of student athletes' significant others are potentially effective tools in concurrently reducing alcohol consumption and some factors that reportedly interfere with sport performance in training and competition. The results also support sport-specific programming to reduce problem behaviors in collegiate athletes, as consistent with other studies.

It makes sense to permit student athletes to choose the type of implementation format (group, individual family) when cost is not an issue, although the group may be more cost-effective. 
Future studies will need to compare group and individual family applications of the experimental condition. The results support the need to examine the relative influence of parents, coaches, peers and teammates when considering alcohol abuse prevention programs in collegiate athletes. The current study appears to indicate these persons may assist student athletes in reducing their alcohol consumption and several factors that reportedly interfere with sport training (i.e., academic problems, injury concerns) and sport competition (i.e., dysfunctional thoughts and stress). This is important because with only a few exceptions, university-based alcohol abuse prevention programs for student athletes have typically excluded the significant others of athletes. Therefore, future studies are warranted to replicate the results of the current pilot study with a larger number of participants and extended follow-up assessment [42].

\section{Acknowledgement}

This research was supported by grants from the Alcohol Beverage Medical Research Foundation (Great Plays Grant Program; 2350-259-775R) and National Institute on Drug Abuse (NIDA; 1R01DA031828). 


\section{References}

1 Doumas DM, Turrisi R, Coll KM, Haralson K (2007) High-risk drinking in college athletes and non-athletes across the academic year. Journal of College Counseling 10: 163-174.

2 Turrisi R, Mallett KA, Mastroleo NR, Larimer ME (2006) Heavy drinking in college students: Who is at risk and what is being done about it? Journal of General Psychology 133: 401-420.

3 Martens MP, Dams-O'Connor K, Beck NC (2006) A systematic review of college student-athlete drinking: Prevalence rates, sport-related factors and interventions. Journal of Substance Abuse Treatment 31: 305-316.

4 Dams-O'Connor K, Martin JL, Martens MP (2007) Social norms and alcohol consumption among intercollegiate athletes: the role of athlete and non-athlete reference groups. Addictive Behavavior 32 2657-2666.

5 Wahesh E, Milroy JJ, Lewis TF, Orsini MM, Wyrick DL (2013) Hazardous drinking by first-year college-athletes: The differential roles of drinking motives, alcohol consequences and season status. Journal of Alcohol \& Drug Education 57: 66-84

6 Martens MP, Dams-O'Connor K, Kilmer JR (2007) Alcohol and drug use among athletes: Prevalence, etiology and interventions. In G. Tenenbaum \& R. C. Eklund (Eds.), Handbook of Sport Psychology (3rd ed., 859-878). New York, NY: John Wiley \& Sons, Inc.

7 Leichliter JS, Meilman PW, Presley CA, Cashin JR (1998) Alcohol use and related consequences among students with varying levels of involvement with college athletics. Journal of American College Health 46: 257-262.

8 Lisha NE, Sussman S (2010) Relationship of high school and college sports participation with alcohol, tobacco and illicit drug use: A review. Addictive Behaviors 35: 399-407.

9 Donohue B, Pitts M, Gavrilova Y, Ayarza A, Cintron KI (2013) A culturally sensitive approach to treating substance abuse in athletes using evidence-supported methods. Journal of Clinical Sport Psychology 7: 98-119.

10 Yusko DA, Buckman JF, White HR, Pandina RJ (2008) Alcohol, tobacco, illicit drugs and performance enhancers: A comparison of use by college student athletes and non-athletes. Journal of American College Health 57: 281-289.

11 NCAA Research (2014) NCAA national study of substance use habits of college student-athletes.

12 Ford JA (2007) Substance use among college athletes: A comparison based on sport/team affiliation. Journal of American College Health 55: 367-373.

13 O'Brien CP, Lyons F (2000) Alcohol and the athlete. Sports Medicine 29: $295-300$

14 Nelson TF, Wechsler H (2001) Alcohol and college athletes. Medicine and Science in Sports Exercise 33: 43-47.

15 Wechsler H, Davenport AE, Dowdall GW, Grossman SJ, Zanakos SI (1997) Binge drinking, tobacco and illicit drug use and involvement in college athletics. Journal of American College Health 45: 195-200.

16 Cadigan JM, Littlefield AK, Martens MP, Sher KJ (2013) Transitions into and out of intercollegiate athletic involvement and risky drinking. Journal of Studies on Alcohol and Drugs 74: 21-29.

17 Martha C, Grelot L, Peretti-Watel P (2009) Participants' sports characteristics related to heavy episodic drinking among French students. International Journal of Drug Policy 20: 152-160.
18 Green K, Nelson TF, Hartmann D (2014) Binge drinking and sports participation in college: Patterns among athletes and former athletes. International Review for the Sociology of Sport 49: 417-434.

19 Borsari B, Murphy JG, Barnett NP (2007) Predictors of alcohol use during the first year of college: Implications for prevention. Addictive Behaviors 32: 2062-2086.

20 Davis R, DeBarros A (2006) In college, first year is by far the riskiest. In USA Today.

21 Larimer ME, Cronce JM (2002) Identification, prevention and treatment: A review of individual-focused strategies to reduce problematic alcohol consumption by college students. Journal of Studies on Alcohol 63: 148-163.

22 Nelson TF, Toomey TL, Lenk KM, Erickson DJ, Winters KC (2010) Implementation of NIAAA College drinking task force recommendations: How are colleges doing 6 years later? Alcoholism: Clinical and Experimental Research 34: 1687-1693.

23 Wechsler H, Kelley K, Weitzman ER, SanGiovanni JP, Seibring M (2000) What colleges are doing about student binge drinking. A survey of college administrators. Journal of American College Health 48: 219-226.

24 Bruce S, Crockett A (2007) APPLE: A comprehensive student athlete substance abuse prevention model. Program presented at the U.S. Department of Education National Meeting on Alcohol and Other Drug Abuse and Violence Prevention in Higher Education, Omaha, NE.

25 Bruce S, Sisk K (2006) APPLE: A comprehensive approach to promoting student athlete wellness and substance abuse prevention. The Peer Educator 89: 8-9.

26 Malloy EA, Goldman M, Kington R (2002) A call to action: Changing the culture of drinking at U.S. colleges. Washington, DC: National Institute on Alcohol Abuse and Alcoholism: Task Force of the National Advisory Council on Alcohol Abuse and Alcoholism.

27 Carey KB, Scott-Sheldon LAJ, Carey MP, DeMartini KS (2007) Individual-level interventions to reduce college student drinking: A meta-analytic review. Addictive Behaviors 32: 2469-2494.

28 Cronce JM, Larimer ME (2011) Individual-focused approaches to the prevention of college student drinking. Alcohol Research \& Health 34: $210-221$.

29 Babor TF, Biddle-Higgins JC, Saunders JB, Monteiro MG (2001) AUDIT: The alcohol use disorders identification test: Guidelines for use in primary health care. Geneva, Switzerland: World Health Organization.

30 Saunders JB, Aasland OG, Babor TF, de la Fuente JR, Grant M (1993) Development of the alcohol use disorders identification test (AUDIT): WHO collaborative project on early detection of persons with harmful alcohol consumption-II. Addiction 88: 791-804.

31 Larimer ME, Cronce JM (2007) Identification, prevention and treatment revisited: Individual-focused College drinking prevention strategies 1999-2006. Addictive Behaviors 32: 2439-2468.

32 Hysong SJ, Best RG, Pugh JA (2006). Audit and feedback and clinical practice guideline adherence: Making feedback actionable. Implement Science 1: 5-3.

33 Gardner B, Whittington C, McAteer J, Eccles MP, Michie S (2010) Using theory to synthesise evidence from behaviour change interventions: The example of audit and feedback. Social Science \& Medicine 70 1618-1625.

34 Thombs DL (2000) A test of the perceived norms model to explain 
drinking patterns among university student athletes. Journal of American College Health 49: 75-83.

35 Doumas DM, Haustveit T, Coll KM (2010) Reducing heavy drinking among first year intercollegiate athletes: A randomized controlled trial of web-based normative feedback. Journal of Applied Sport Psychology 22: 247-261.

36 Doumas D, Haustveit T (2008) Reducing heavy drinking in intercollegiate athletes: Evaluation of a web-based personalized feedback program. Sport Psychologist 22: 212-228.

37 Cimini MD, Monserrat JM, Sokolowski KL, Dewitt-Parker JY, Rivero EM, et al. (2015) Reducing high-risk drinking among student-athletes: The effects of a targeted athlete-specific brief intervention. Journal of American College Health 63: 343-352.

38 Dimeff L A, Baer JS, Kivlahan DR, Marlatt GA (1999) Brief alcohol screening and intervention for college students (BASICS): A harm reduction approach. New York, NY: Guilford Press.

39 Martens MP, Kilmer JR, Beck NC, Zamboanga BL (2010) The efficacy of a targeted personalized drinking feedback intervention among intercollegiate athletes: A randomized controlled trial. Psychology of Addictive Behaviors 24: 660-669.

40 Turrisi R, Wiersma KA, Hughes KK (2000) Binge-drinking-related consequences in college students: Role of drinking beliefs and mother-teen communications. Psychology of Addictive Behaviors 14: 342-355.

41 Turrisi R, Jaccard J, Taki R, Dunnam H, Grimes J (2001) Examination of the short-term efficacy of a parent intervention to reduce college student drinking tendencies. Psychology of Addictive Behaviors 15: 366-372.

42 Turrisi R, Larimer ME, Mallett KA, Kilmer JR, Ray AE, et al. (2009) A randomized clinical trial evaluating a combined alcohol intervention for high-risk college students. Journal of Studies on Alcohol and Drugs 70: 555-567.

43 Tevyaw TO, Borsari B, Colby SM, Monti PM (2007) Peer enhancement of a brief motivational intervention with mandated college students. Psychology of Addictive Behaviors: Journal of the Society of Psychologists in Addictive Behaviors 21: 114-119.

44 Giacobbi PR, Lynn TK, Wetherington JM, Jenkins J, Bodenforf M, et al. (2004). Stress and coping during the transition to university for firstyear female athletes. The Sport Psychologist 18: 1-20.

45 Donohue B, Silver N, Dickens Y, Covassin T, Lancer K (2007) Development and initial psychometric evaluation of the sport interference checklist. Behavior Modification 31: 937-957. 